\title{
Ultrastructural changes and nestin expression accompanying compensatory renal growth after unilateral nephrectomy in adult rats
}

This article was published in the following Dove Press journal: International Journal of Nephrology and Renovascular Disease 21 February 2017

Number of times this article has been viewed

\author{
Mohamed Ahmed Eladl ${ }^{1,2}$ \\ Wael M Elsaed ${ }^{2,3}$ \\ Hoda Atef ${ }^{4}$ \\ Mohamed El-Sherbiny ${ }^{2}$ \\ 'Department of Basic Medical \\ Sciences, University of Sharjah, \\ Sharjah, United Arab Emirates; \\ ${ }^{2}$ Anatomy and Embryology \\ Department, Faculty of Medicine, \\ Mansoura University, Mansoura, \\ Egypt; ${ }^{3}$ Anatomy and Embryology \\ Department, Faculty of Medicine, \\ Taibah University, Madinah, Saudi \\ Arabia; ${ }^{4}$ Department of Histology, \\ University of Mansoura, Mansoura, \\ Egypt
}

Background: Several renal disorders affect the glomerular podocytes. Compensatory structural and functional changes have been observed in animals that have undergone unilateral renal ablation. These changes occur as a pliant response to quench the increased functional demand to maintain homeostasis of fluid and solutes. Nestin is an intermediate filament protein present in the glomerular podocytes of the adult kidney and is linked with the maintenance of its foot process structure. Structural changes in the podocytes ultimately restructure the filtration barrier. Very few studies related to the ultrastructural and histopathologic changes of the podocytes are documented. The present study aimed to assess the histopathologic changes at the ultrastructural level in the adapted kidney at different time intervals following unilateral renal ablation in adult rats and its relation with nestin.

Methods: Forty-eight rats were divided into four groups ( $n=12$ in each group). The animals of Group A were control naïve rats, while the group B, group C and group D animals underwent left unilateral nephrectomy and the remaining right kidney was removed on days 10, 20 and 30 , respectively. Each group included four sham-operated rats, which were sacrificed at the same time as the naïve rats. Each nephrectomized sample was weighed and its sections were subjected to hematoxylin and eosin examination, transmission electron microscopic study as well as immunostaining using the intermediate filament protein nestin.

Results: No difference was found between the kidney sections from the control group and the sham-operated groups. A significant increase in the weight of the right kidneys was noted in groups $\mathrm{B}, \mathrm{C}$ and $\mathrm{D}(P<0.001)$. The ultrastructural adaptive changes seen in the glomeruli of group $\mathrm{B}$ were subsequently reduced in groups $\mathrm{C}$ and $\mathrm{D}$. This finding corresponded to a similar pattern of nestin expression in the podocytes, which showed significant increase in group B followed by reduced expression in groups $\mathrm{C}$ and $\mathrm{D}$. Histopathologic and transmission electron microscopic evaluation of group B showed signs of kidney injury. On the other hand, group C animals showed markedly reduced renal adaptive changes and similar changes were also noted in group D.

Conclusion: Correlation between nestin expression and the ultrastructural changes confirms that nestin has a role in increasing the mechanical stability of the podocytes in order to enhance their morphologic changes in response to the tensile glomerular capillary wall. However, further studies investigating more remote ultrastructural changes and their relation with nestin expression are needed to confirm this relationship.

Keywords: glomerular proliferation, podocytes, basement membrane, subpodocytic space, TEM, nestin, nephrectomy, compensatory
Correspondence: Mohamed Ahmed Elad University of Sharjah, PO Box 27272 , Sharjah, United Arab Emirates Email meladı@sharjah.ac.ae
International Journal of Nephrology and Renovascular Disease 2017:10 6I-76

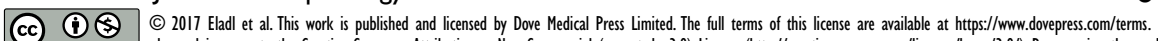

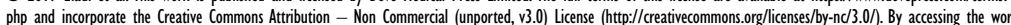
you hereby accept the Terms. Non-commercial uses of the work are permitted without any further permission from Dove Medical Press Limited, provided the work is properly attributed. For permission for commercial use of this work, please see paragraphs 4.2 and 5 of our Terms (https://www.dovepress.com/terms.php). 


\section{Introduction}

Unilateral nephrectomy is a major surgery indicated for kidney donation ${ }^{1}$ or conditions that lead to poorly functioning or nonfunctioning kidney as renal cell or urothelial cancer. ${ }^{2}$ After unilateral nephrectomy, the remaining kidney undergoes structural and functional changes as a pliant response to quench the increased functional demand to maintain the homeostasis of fluid and solutes in the body. ${ }^{3,4}$ The compensatory renal hypertrophy causes an increase in weight and/ or volume of the remaining kidney of the adult animals..$^{5-8}$ The nephrogenesis in rats and mice is accomplished during their neonatal period, while in humans, it occurs prenatally, and therefore, the renal growth that occurs does not include new nephron formation. ${ }^{9} 10$ The nature of this compensatory growth was found to be rather hypertrophic than hyperplastic. ${ }^{11}$

According to the studies by Fong et al, the adaptive enlargement of the renal tubules and glomeruli that occurs in response to the decreased renal mass during the postnatal and prenatal phases varies from the adaptation that follows when there is a reduction in the renal tissue in adulthood. ${ }^{12}$ This alteration occurs faster with a better result in younger animals compared to adults. ${ }^{13-15}$

After unilateral nephrectomy, the major instant functional adaptation is a gradual increase in the mean glomerular filtration rate. ${ }^{16,17}$ This increase is initiated due to the variations in renal hemodynamics, such as an increased renal blood flow coupled with decreased afferent arteriole resistance caused by renal cortical vasodilatation. ${ }^{16,18-20} \mathrm{An}$ increase in fractional excretion of water and solutes following compensatory adaptations in tubules is due to a reduction in the fractional reabsorption of sodium and water, increased potassium secretion or enhanced flow of tubular fluid. ${ }^{21-24}$ Adaptive changes in glomeruli and tubules in response to nephron deficiency can increase the risk of hypertension and renal disease in the long run. ${ }^{12}$

Many biochemical parameters were found to be activated during compensatory renal hypertrophic responses, such as angiotensin II, $p$-aminohippurate, nitric oxide, growth factors and proto-oncogenes. ${ }^{4,12,25,26}$ At the histopathologic level, kidney weight was used as the main most prominent indicator of the compensatory hypertrophy. ${ }^{3,8}$

The compensatory growth can affect the glomeruli, proximal and distal convoluted tubules and also the cortical collecting ducts, ${ }^{7,27-30}$ with reports specifying that this growth occurs primarily in the cortex, especially confined to the proximal convoluted tubules. ${ }^{11}$ The growth pattern resembles that of the natural growth of kidney during the postnatal period where hypertrophy of the proximal tubules is more than that of distal tubules. ${ }^{12}$

Glomerular podocytes are highly differentiated cells with a complex cytoarchitecture that lines the outer aspect of the glomerular basement membrane. Various human and experimental renal diseases affect the glomerular podocytes that form the final filtration barrier, leading to proteinuria. ${ }^{31-33}$ Molecular changes of the slit diaphragm following any pathologic alterations in the podocytes will eventually result in restructuring of the arrangement in the foot process with the fusion of filtration slits and apical shift of the slit diaphragm. ${ }^{34-36}$

Nestin, an intermediate filament protein primarily identified in neural stem cells, is transiently expressed in the glomerular podocytes of the adult kidney that are linked with the maintenance of the foot process structure..$^{37,38}$

Although the functional changes in the remaining kidney are thoroughly studied in researches ${ }^{39}$ very few studies related to the ultrastructural and histopathologic changes of the podocytes are documented..$^{40,41}$

The present study aimed to assess the histopathologic changes at the ultrastructural level in the adapted kidney at different time intervals following unilateral renal ablation in adult rats and its relation with nestin.

\section{Materials and methods \\ Experimental animals and grouping}

Forty-eight female Sprague Dawley rats (200-250 g) were divided into four groups ( $\mathrm{n}=12$ in each group). The animals were housed at the animal care facility of Mansoura Experimental Research Center at the School of Medicine Mansoura University. All protocols were followed as per the guidelines for the Care and Use of Laboratory Animals; the study was approved by Mansoura Faculty of Medicine-Institutional Research Board (MFM-IRB). The animals of Group A were control naïve rats. While rats of Group B, Group C and Group $\mathrm{D}$ underwent left unilateral nephrectomy and the remaining right kidney was removed on days 10,20 and 30, respectively. Each group included four randomly selected rats used as sham-operated animals, which were sacrificed at the same time as the naïve rats.

\section{Surgical procedure and sampling}

The animals were anesthetized using Nembutal $(60 \mathrm{mg} / \mathrm{kg}$ body weight intraperitoneal), following which midline incision on the abdomen was carried out extending from the xiphoid process to the infraumbilical region. The muscles were then retracted and the contents of the abdomen were 
explored till the kidneys were exposed. The blood supply of the left kidney was identified, isolated and ligated $1 \mathrm{~cm}$ distal from the renal hilum. The renal vessels along with the ureter are incised close to the hilar ligature, leaving a small part of the tissue to rule out any possibility of sliding of tied structures. After that, the kidney was dissected out from the retroperitoneal space and transferred to a small beaker of saline for further dissection. The sham animals were manipulated, but the renal vessels and the ureter were not ligated. After the above-mentioned procedures were carried out, the contents of the abdomen in all animals were gently returned to their anatomical positions. The abdominal muscles and the skin were sutured in layers with sterile 3-0 chromic gut sutures and 3-0 Ethilon monofilament nylon suture and cutting needle. The sutured area was cleaned with Iodophor solution and was let to dry before dressing up the wound with sterile gauze and tape.

Further to this, the animals were gently positioned in a warm recovery cage on its right side with free access to food and water ad libitum. Following their recovery, the animals were transferred to their usual cages until the next sampling time.

All the animals were sacrificed by injecting a lethal dose of Nembutal intravenously, which was followed by removal of their right kidneys quickly at the end of 10,20 and 30 days, respectively. Each nephrectomized specimen was weighed before decapsulation, which was further blot dried and weighed before being cut into strips.

Using a dissection microscope, the specimens were sliced into 25 pieces with $1 \mathrm{~mm}$ thickness that ran perpendicular to the long axis of the kidney passing from the cortex to the medulla. The slices were maintained in fresh fixative for an additional 3 hours at room temperature and rinsed with $0.1 \mathrm{M}$ phosphate buffer of $\mathrm{pH} 7.2$ many times before storing them overnight at a temperature of $4^{\circ} \mathrm{C}$.

The above specimens were further fixed in phosphatebuffered $1 \%$ osmium tetroxide, dehydrated with acetone and embedded in Araldite. From these primary samples, three blocks were randomly picked from each animal, sectioned at $0.5 / \mathrm{mm}$ with a Reichert OmU 2 ultramicrotome and stained with methylene blue for further morphometric analysis.

For transmission electron microscopy, the prepared slices of kidney were further sectioned into small pieces and fixed in $2.5 \%$ buffered glutaraldehyde with $0.1 \mathrm{M}$ cacodylate buffer at $\mathrm{pH} 7.4$ and $4^{\circ} \mathrm{C}$ for 3 hours. The fixed pieces were then washed in $0.1 \mathrm{M}$ cacodylate buffer, and $1 \%$ osmium tetroxide was used for postfixation for 1 hour. Ethanol gradient series was used for dehydration, and the specimens were embedded in Epon. Ultramicrotome was used to prepare ultrathin sections (60-90 nm). The specimens were observed using a Jeol field emission scanning electron microscope JSM-6390LV. The thickness of the basement membrane was measured.

For immune staining, rabbit N5413 anti-nestin antibody against rat polyclonal antibody was used (Sigma-Aldrich Co., St Louis, MO, USA). The tissues that were embedded in paraffin were sliced into $5 \mu \mathrm{m}$ thickness and deparaffinized with xylene and increasing grade of ethanol. The specimens were incubated with primary antibodies (or equal amounts of irrelevant IgG), counterstained with hematoxylin, stabilized with mounting medium and examined as detailed in the accompanying reagent kit.

Slides and electron microscopy (EM) images were digitized and saved as TIFFs. The results obtained from the images were evaluated on Intel ${ }^{\circledR}$ Core $I 3^{\circledR}$ built computer using Video Test Morphology ${ }^{\circledR}$ software (Saint-Petersburg, Russia) with a particular built-in routine for calibrated distance measurement and immune staining quantification (Figure 1A, B).

Morphometric evaluation comprising the 15 fields containing Bowman's space area on individual slides obtained from the kidney sections was done on hematoxylin and eosin-stained paraffin sections using Image $\mathrm{J}$ software (version 1.42; National Institutes of Health, Bethesda, MD, USA) analysis system at $\times 400$ magnification. The areas of the Bowman's space were measured to assess microanatomical alteration, if any, to the renal corpuscle of the kidneys (Figure 2A, B).

\section{Statistical analysis}

The obtained values were charted, coded, evaluated and the statistical calculations were carried out using Instat-3 computer program(Graph Pad Software Inc. v2. 04, San Diego, CA, USA).

All values were presented as mean \pm standard deviation (SD), and significance was calculated at $p<0.05$. One way analysis of variance (ANOVA) followed by Tukey-Kramer multiple comparisons test for statistical comparison between parametric data and linear regression analysis for the best fitting line of all the standard points.

\section{Results}

The kidney sections obtained from the control group and the sham-operated groups were identical, and so, all the sham-operated groups were considered as control. The kidney weight showed significant progressive increase from the 10 days group (B) to the 30 days group (D) (Figure 3). 
A

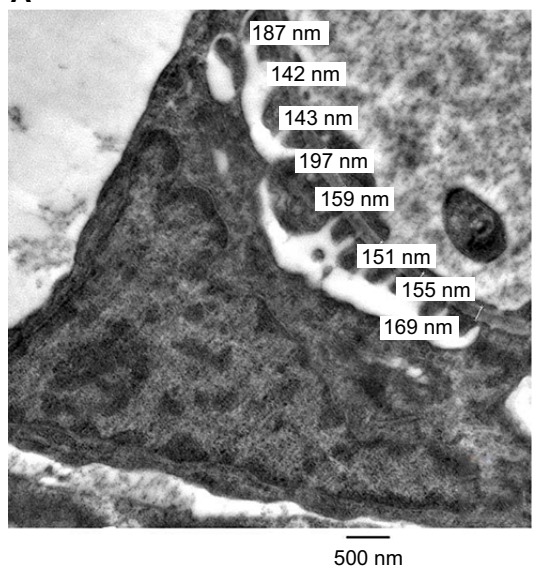

B

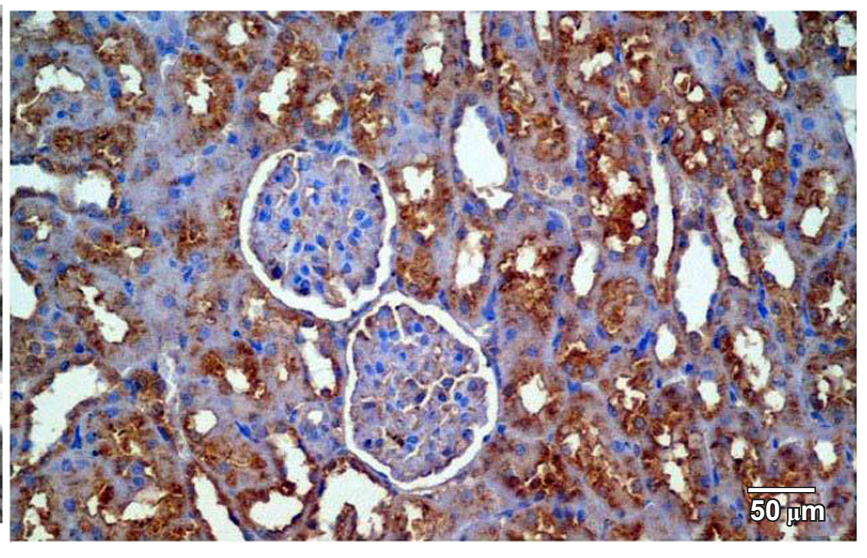

Figure I Measurement of the basement membrane thickness and immune staining quantification. Notes: (A) Measurement of the basement membrane thickness. (B) Immune staining quantification.

A

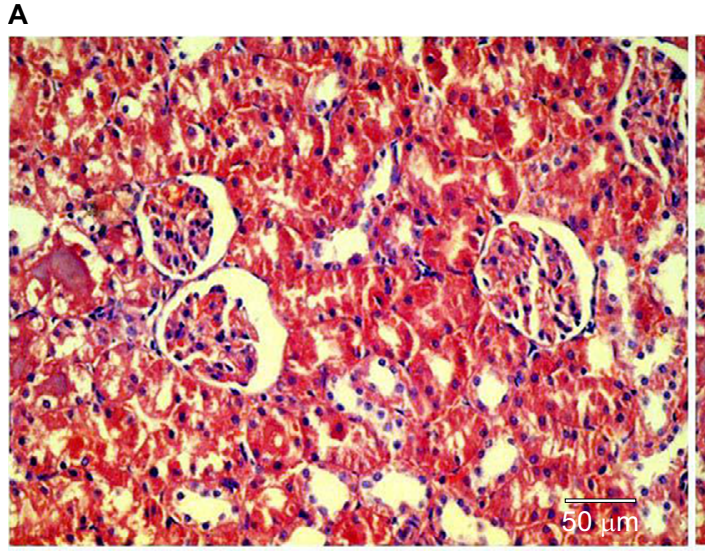

B

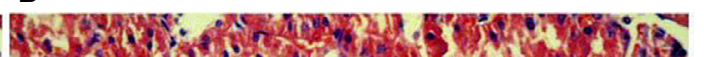

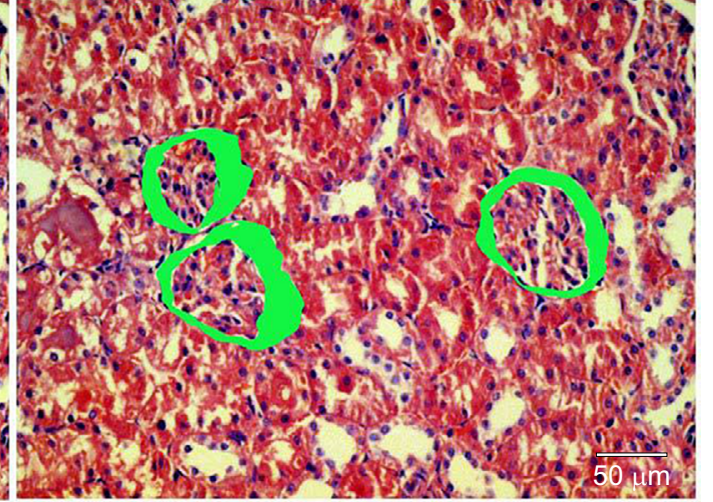

Figure 2 Image software measurement of the Bowman's space of hematoxylin and eosin-stained renal sections. (A) Renal cortex showing renal glomeruli with Bowman's space and proximal tubules. (B) The Bowman's space areas were identified and measured by Imagej program.

Compared to body weight, the percentage of the kidney weight also showed a significant increase in the 10 days group (B), 20 days group (C) and 30 days group (D), compared to the control group (A) (Figures 4 and 5 and Table 1).

Hematoxylin and eosin-stained section of the kidney of animals belonging to the 10 days group (B) showed a decrease in the glomerular area with an expansion in Bowman's space, when compared to the control group (A). These changes decreased gradually from the 20 days group (C) to the 30 days group (D). Although the morphometric analysis of the microanatomical alteration of Bowman's space area showed nonsignificant increase in its surface area, it was larger in the 10 days group (B) and gradually decreased in the 20 days group (C) and the 30 days group (D) (Figures 6 and 7 and Table 1).

Kidney specimens stained with anti-nestin antibody in the control group (A) revealed positive normal diffuse nestinstained cells, compared to the weaker expression of the 10 days group (B). Kidneys of the 20 days group (C) showed a significant increase in nestin-positive cells, which was markedly reduced in the 30 days group (D) but still more positive than the control. Immune staining quantification of the slides showed significant decrease in the antibody expression of the 10 days group (B) compared to the controls (A). The 20 days group $(C)$ showed the highest expression which was significant compared to groups $\mathrm{A}$ and $\mathrm{B}$, while the antibody expression decreased significantly in the 30 days group (D) compared to groups B and C (Figures 8 and 9 and Table 1).

Statistical analysis related to the thickness of the basement membrane of all four groups showed significant increase in the thickness of the membrane in the animals of 10 days group (B) compared to the control group (Figures 1, 10 and 11).

Ultrathin sectioning using transmission electron microscopy showed that the animals in the control group had a normal arrangement of the renal corpuscle with renal glomeruli. The single-layered visceral epithelial cells (podocytes) appeared with major, minor cytoplasmic processes and footplates reaching the basement membrane, and were separated by the filtration slits. They showed large cell bodies 


\begin{tabular}{|c|c|c|c|c|c|}
\hline & Control group & 10 days group & 20 days group & 30 days group & $P$-value \\
\hline Mean & 1.16 & 1.31 & 1.53 & 1.70 \\
\hline SD & 0.02 & 0.06 & 0.05 & 0.06 \\
\hline P1 & & $<0.001^{*}$ & $<0.001^{*}$ & $<0.001^{*}$ \\
\hline P2 & & & $<0.001^{*}$ & $<0.001^{*}$ & $<0.001^{*}$ \\
\hline P3 & & & & & $<$ \\
\hline
\end{tabular}

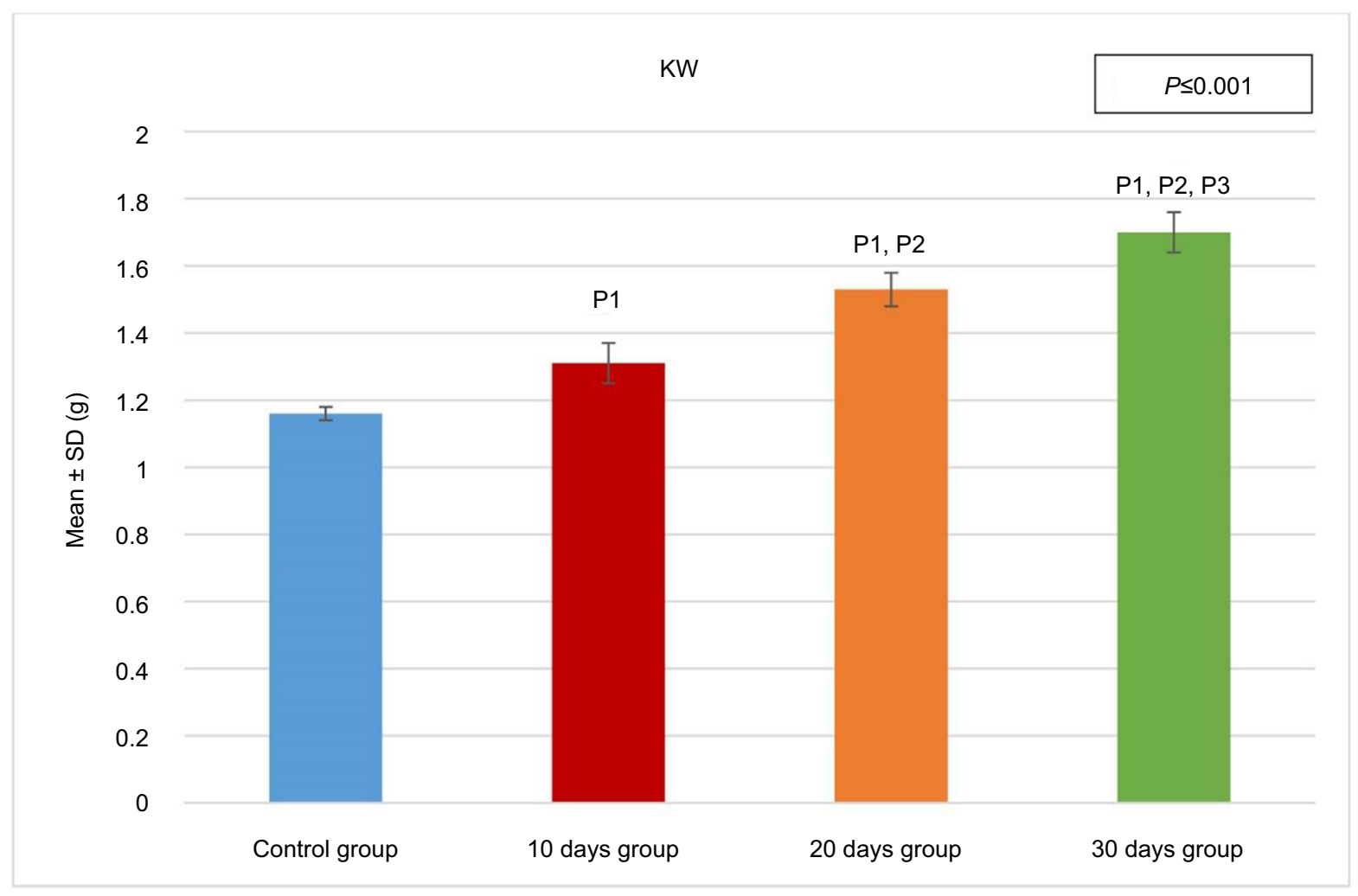

Figure $3 \mathrm{KW}$ of the four groups. Test used was ANOVA followed by post hoc Tukey. *Significant.

Abbreviations: ANOVA, analysis of variance; KW, kidney weight; SD, standard deviation; P, probability; PI, significance versus control group; P2, significance versus I0 days group $\mathrm{P} 3$, significance versus 20 days group.

(perikarya) protruding into the Bowman's space. The proximal convoluted tubule cell appeared lying on the basement membrane. The cell had rounded euchromatic nucleus, basal arrangement of elongated mitochondria, lysosomes and also microvilli at the luminal border (Figure 12A-C).

EM examination of the 10 days group (B) showed disruption of the Bowman's basement membrane with widening of the subpodocytic space. Podocytes showed disrupted minor processes, irregular nuclei, prominent mitochondria and numerous lysosomes. The proximal convoluted tubules appeared with disrupted basement membrane. The lining cells had basal disarrangement of elongated mitochondria, but with microvilli at the luminal border that was still intact (Figure 13A-C).

EM examination of the 20 days group (C) showed podocytes with disrupted irregular nucleus and minor processes. Condensation of the glomerular basement membrane with widened subpodocytic space was also seen. Some red blood 


\begin{tabular}{|c|c|c|c|c|c|}
\hline & Control group & 10 days group & 20 days group & 30 days group & $P$-value \\
\hline Mean & 343.00 & 362.75 & 345.50 & 326.42 \\
\hline SSD & 13.66 & 142.62 & 12.03 & 11.64 \\
\hline P1 & & $0.003^{*}$ & 0.96 & $0.016^{*}$ & $<0.001^{*}$ \\
\hline P2 & & & $0.01^{*}$ & $<.005^{*}$ \\
\hline
\end{tabular}

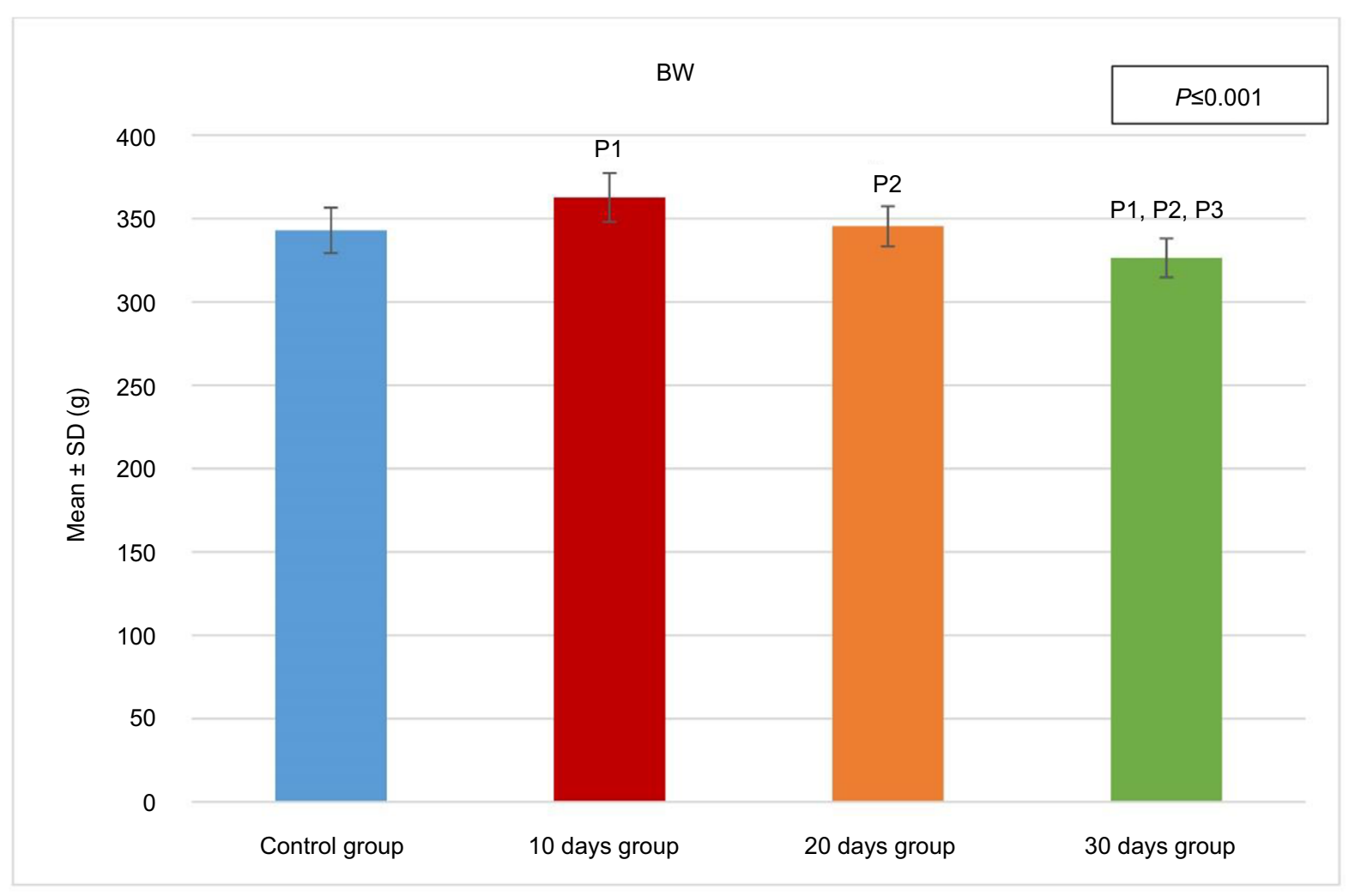

Figure 4 BW of the four groups. Test used was ANOVA followed by post hoc Tukey. *Significant.

Abbreviations: ANOVA, analysis of variance; BW, body weight; SD, standard deviation; P, probability; PI, significance versus control group; P2, significance versus I0 days group P3, significance versus 20 days group.

cells were seen in the glomerular capillaries. The cell lining of the proximal convoluted tubules showed thickened basement membrane. The cell has enlarged open face nucleus with irregular mitochondria, lysosomes and microvilli at the luminal border. The cytoplasm showed multiple vacuoles (Figure 14A-D).

EM examination of the 30 days group (D) showed podocytes with irregular nucleus and minor processes. Thickened glomerular basement membrane with widened subpodocytic space was also noted. The proximal convoluted tubule lining the cells was lying on thickened basement membrane. The cell had irregular enlarged nuclei with an irregular arrangement of mitochondria and lysosomes; numerous vacuoles and loss of microvilli were also noticed (Figure 15A-C).

\section{Discussion}

The increasing demand for renal transplantation as well as for nephrectomy necessitates the need to follow-up the 


\begin{tabular}{|c|c|c|c|c|c|}
\hline & Control group & 10 days group & 20 days group & 30 days group & $P$-value \\
\hline Mean & 0.338 & 0.361 & 0.445 & 0.521 \\
\hline ISD & 0.018 & 0.018 & 0.019 & 0.025 \\
\hline P1 & & 0.051 & $<0.001^{*}$ & $<0.001^{*}$ \\
\hline P2 & & & $<0.001^{*}$ & $<0.001^{*}$ & $<0.001^{*}$ \\
\hline P3 & & & & & $<$ \\
\hline
\end{tabular}

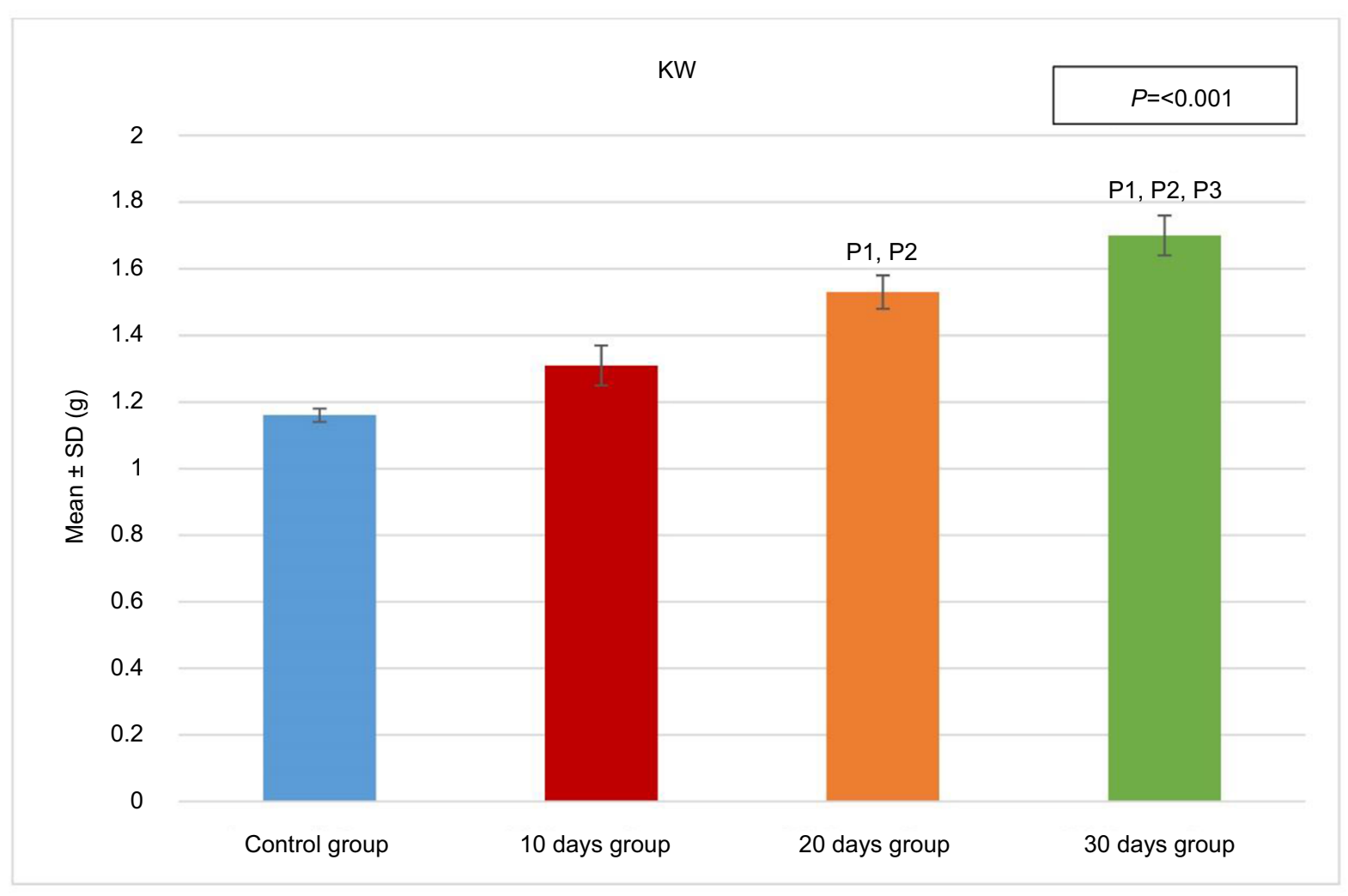

Figure $5 \mathrm{KW} /$ body weight \% of the four groups. Test used was ANOVA followed by post hoc Tukey. *Significant.

Abbreviations: ANOVA, analysis of variance; KW, kidney weight; SD, standard deviation; P, probability; PI, significance versus control group; P2, significance versus I0 days group $\mathrm{P} 3$, significance versus 20 days group.

Table I Comparative table of all groups regarding kidney weight, Bowman's space area, nestin expression and basement membrane thickness as found in EM

\begin{tabular}{lllll}
\hline Experimental groups & Control group & 10 days group & 20 days group & 30 days group \\
\hline Kidney weight $(\mathrm{g})$ & $1.16 \pm 0.02$ & $1.31 \pm 0.06$ & $1.53 \pm 0.05$ & $1.70 \pm 0.06^{*}$ \\
Bowman's space area $\left(\mu \mathrm{m}^{2}\right)$ & $18,282.33 \pm 6,094.1 \mathrm{I}$ & $23,838.5 \pm 7,653.8^{*}$ & $23,571.75 \pm 7,857.25^{*}$ & $21,931.4 \pm 2,500.94$ \\
Nestin expression $(\mu \mathrm{m})$ & $23,198,170 \pm 7,732,723$ & $10,828,490 \pm 3,609,496$ & $42,169,080 \pm 14,056,360^{*}$ & $25,430,000 \pm 8,476,667^{*}$ \\
Basement membrane & $0.162 \pm 0.04$ & $0.25 \pm 0.054^{*}$ & $0.186 \pm 0.085$ & $0.197 \pm 0.059$ \\
thickness as found in EM $(\mathrm{nm})$ & & & &
\end{tabular}

Abbreviation: EM, electron microscopy.

Notes: Data presented as mean \pm SD. *Significant. 


\begin{tabular}{|c|c|c|c|c|c|}
\hline & Control group & 10 days group & 20 days group & 30 days group & $P$-value \\
\cline { 1 - 5 } Mean & $18,282.33$ & $23,838.5$ & $23,571.75$ & $21,931.4$ & \\
\cline { 1 - 5 } \pm ISD & $6,094.11$ & $7,653.8$ & $7,857.25$ & $2,500.94$ & \\
\hline
\end{tabular}

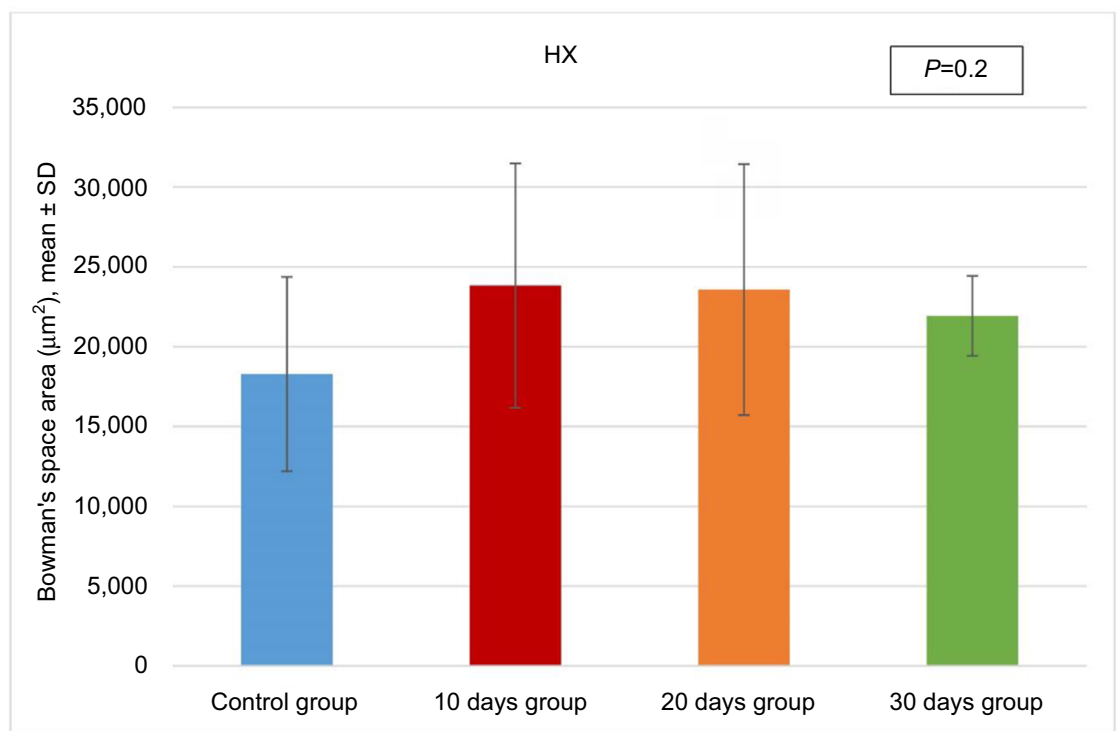

Figure 6 Morphometric analysis of the microanatomical alteration of Bowman's space area in the hematoxylin and eosin-stained sections. Test used was ANOVA followed by post hoc Tukey.

Abbreviations: ANOVA, analysis of variance; HX, hematoxylin; SD, standard deviation; P, probability.

A

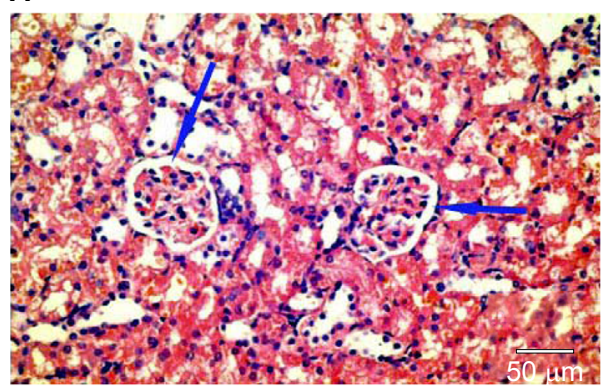

C

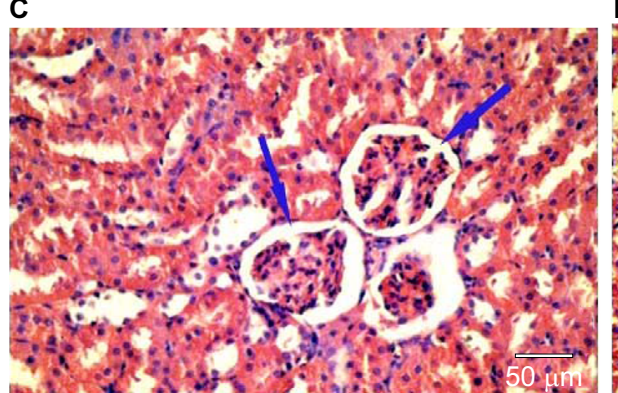

B

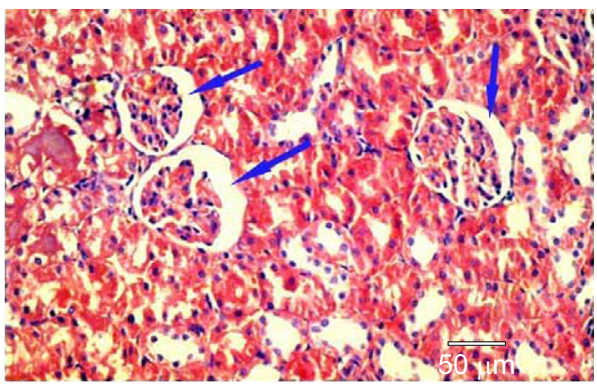

D

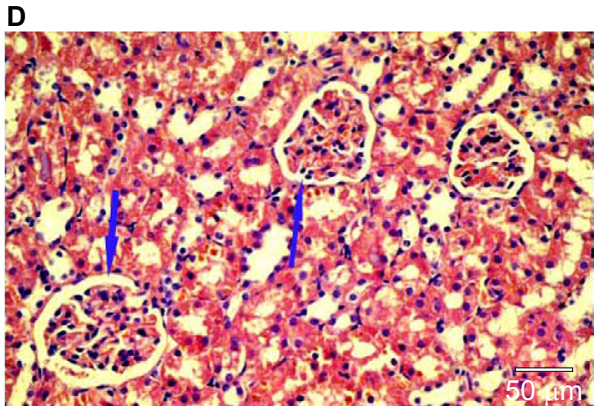

Figure 7 Hematoxylin and eosin-stained section of the kidney showing reduction in glomerular area and expansion of Bowman's space (blue arrows) in group (B) as compared with the control group (A). These changes decreased gradually from group (C) to group (D). 


\begin{tabular}{|c|c|c|c|c|c|}
\hline & Control group & 10 days group & 20 days group & 30 days group & $P$-value \\
\hline Mean & $23,198,170$ & $10,828,490$ & $42,169,080$ & $25,430,000$ \\
\hline ISD & $7,732,723$ & $3,609,496$ & $14,056,360$ & $8,476,667$ \\
\hline P1 & & $0.02^{*}$ & $<0.001^{*}$ & 0.9 \\
\hline P2 & & & $<0.001^{*}$ & $0.006^{*}$ & \\
\hline P3 & & & & $0.001^{*}$ & \\
\hline
\end{tabular}

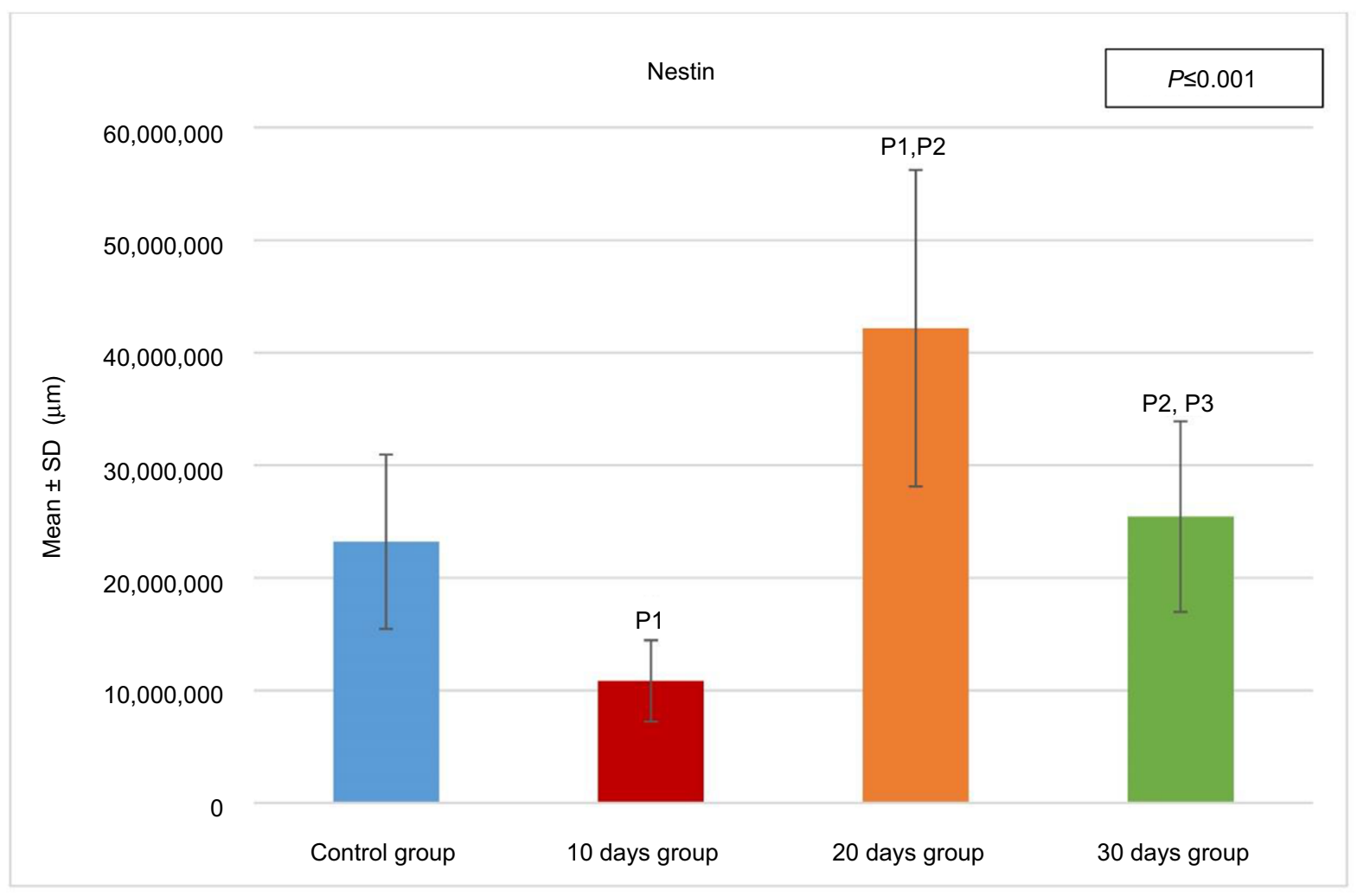

Figure 8 Anti-nestin antibody expression of the four groups. Test used was ANOVA followed by post hoc Tukey. *Significant.

Abbreviation: ANOVA, analysis of variance; SD, standard deviation; P, probability; PI, significance versus control group; P2, significance versus I0 days group; P3, significance versus 20 days group.

remaining kidney, particularly at the micropathologic level, in order to find a method to overcome the consequent possible pathologic changes. ${ }^{42,43}$

A 53\% reduction in the glomerular filtration rate has been observed immediately after unilateral nephrectomy. ${ }^{44}$ The remaining kidney is, therefore, challenged to face prolonged hyperfiltration..$^{45}$ Hemodynamics and structural changes contribute to increased renal blood flow and decreased renal vascular resistance. ${ }^{20,46}$ These changes were suggested to be mediated by nitric oxide and they continue for 1 week. Thereafter, the increased renal blood flow is corrected by the structural changes in the form of renal hypertrophy. ${ }^{19}$ Hypertrophy of the kidney is accompanied by hyperplasia of the cell lining the renal tubules, particularly the proximal convoluted ones with increase in the sizes of the renal corpuscles. ${ }^{47}$

We found in our study a significant progressive increase in kidney weight as well as in the percentage of the kidney to the 
A

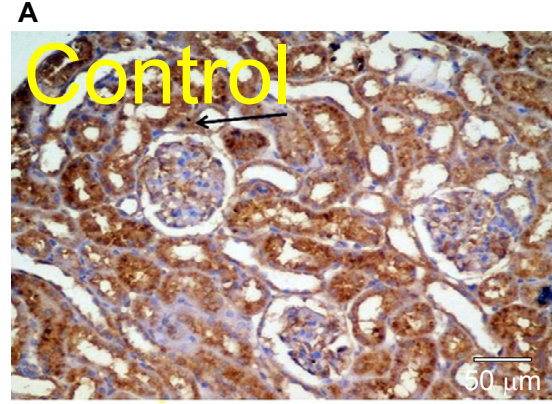

C

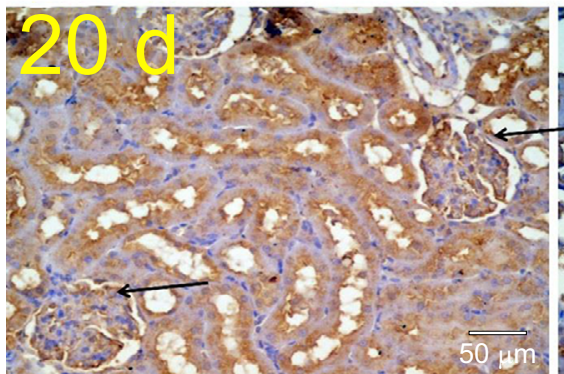

B

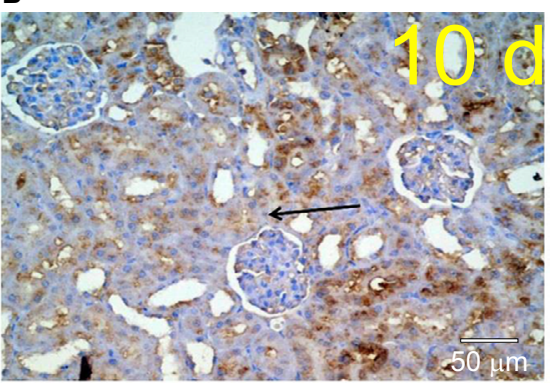

D

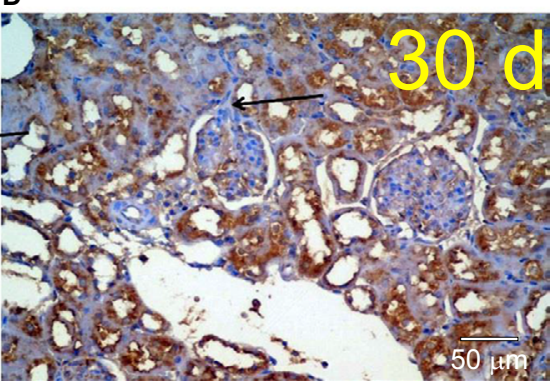

Figure 9 Kidney specimens stained with anti-nestin antibody from a normal healthy control group reveals positive normal diffuse nestin-stained cells (A) compared to the weaker expression of the 10 days (d) nephrectomized rats (B). Kidneys of 20 days nephrectomized rats reveal a marked significant increase in nestin-positive cells (C). It is markedly reduced in the 30 days group $(\mathbf{D})$, but still more positive than the controls.

\begin{tabular}{|c|c|c|c|c|c|}
\hline & Control group & 10 days group & 20 days group & 30 days group & $P$-value \\
\cline { 1 - 5 } Mean & 0.162 & 0.25 & 0.186 & 0.197 & \multirow{2}{*}{$0.02^{*}$} \\
\hline $\pm S D$ & 0.04 & 0.054 & 0.085 & 0.059 & \\
\hline P1 & & $0.017^{*}$ & 0.9 & 0.76 & 0.3 \\
\hline P2 & & & 0.15 & 0.99 & \\
\hline P3 & & & & & \\
\hline
\end{tabular}

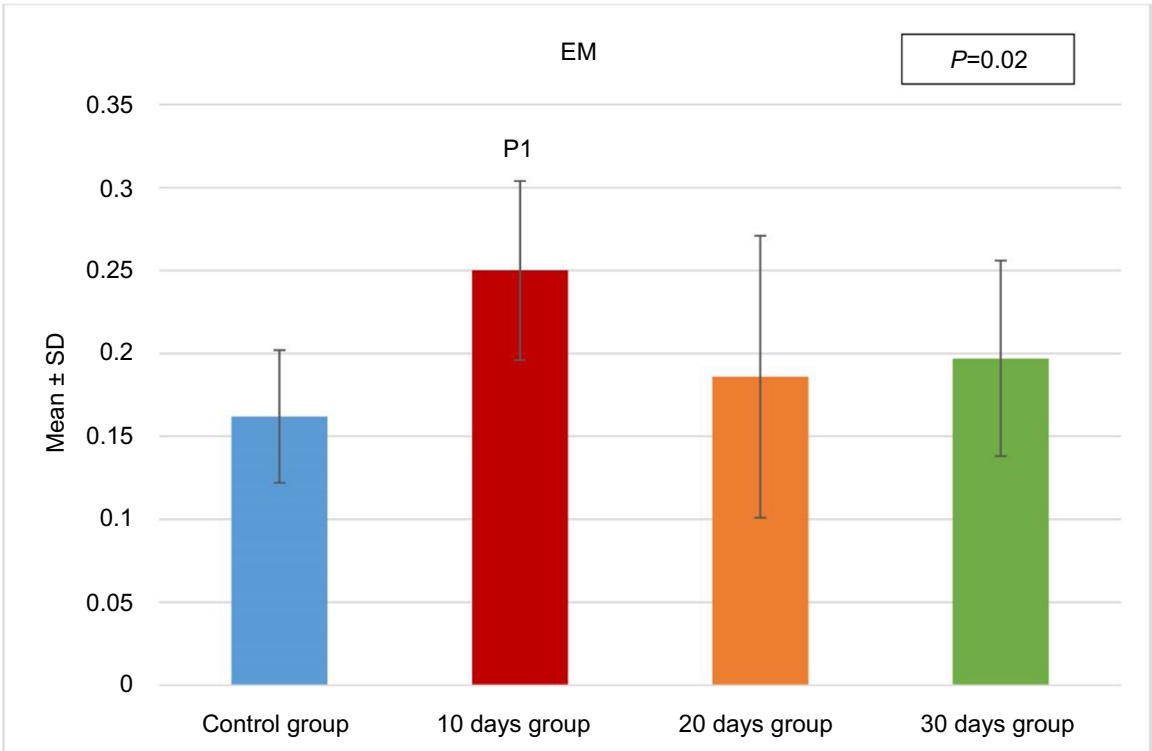

Figure 10 Basement membrane thickness of the four groups as measured by EM. Test used was ANOVA followed by post hoc Tukey. *Significant.

Abbreviations: ANOVA, analysis of variance; SD, standard deviation; P, probability; PI, significance versus control group; P2, significance versus I0 days group; P3, significance versus 20 days group. 
A

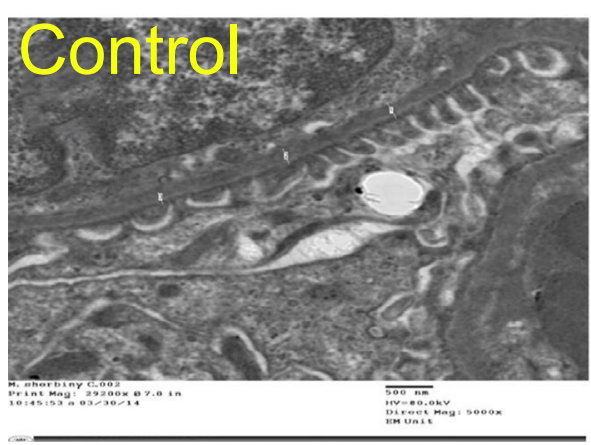

C

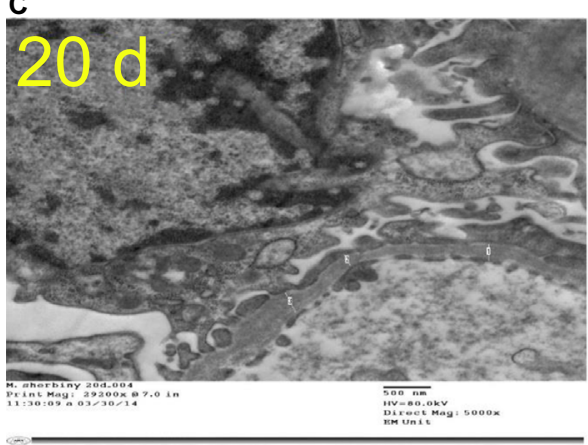

B

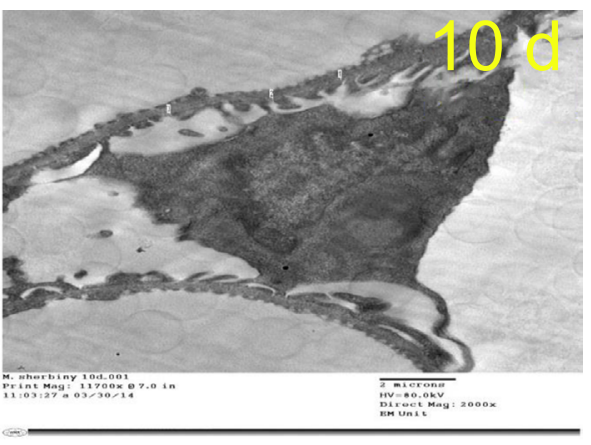

D

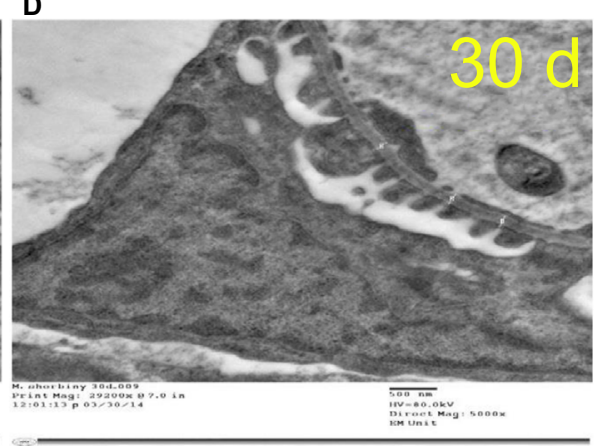

Figure II The thickness of the basement membrane of the four groups (A, B, C, and D) showed significant increase in 10 days group (B) compared to the control group (A), and non significantly increased in groups $\mathbf{C}$ and $\mathbf{D}$.

A

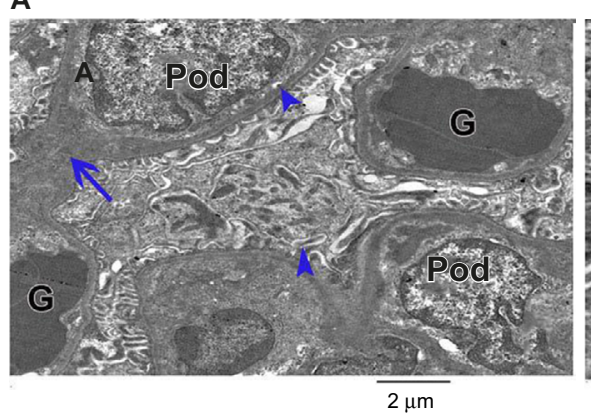

B

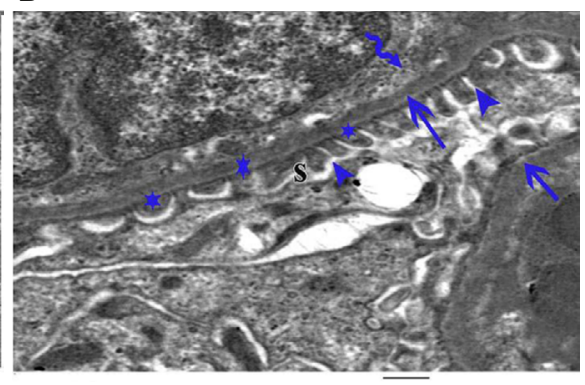

$500 \mu \mathrm{m}$
C

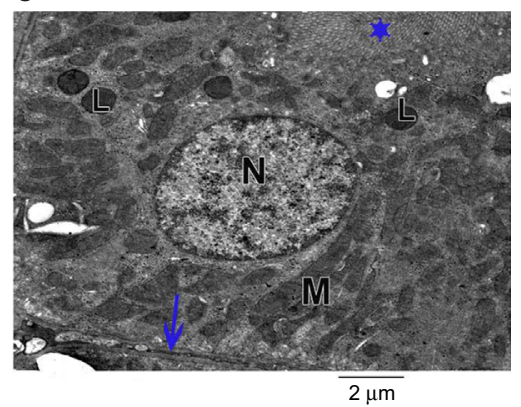

Figure 12 An electron micrograph of ultrathin section of the renal cortex of the control rat. (A) Shows the renal corpuscle with renal glomeruli (G). Podocytes (Pod) appear with major (arrows) and minor processes (arrow head). (B) Shows the glomerulus having normal basement membrane (arrows), and podocytes showing major process (curved arrows), minor processes (arrow heads) and footplates (star) appear in the subpodocytic space (S). (C) Shows the proximal convoluted tubule lining cell lying on the basement membrane (arrow). The cell has rounded euchromatic nucleus $(\mathrm{N})$, basal elongated mitochondria (M), lysosomes (L) and microvilli at the luminal border (star).

body weight in the three nephrectomized groups and it reached its peak in the 30 days group (D). This increase in weight is an indicator of both hyperplasia and hypertrophy of the remaining kidney, which has been reported in similar studies. ${ }^{10,39,48}$

Some authors have reported that the increase in kidney weight is age related. ${ }^{10,46}$ It is more noticeable in fetuses and youngsters than in adults, as the process of nephrogenesis is still not completed and, therefore, the existence of a nephrogenic zone would allow the development of new cells. However, the increased number of nephrons, which seems to be beneficial, could possibly increase the vulnerability to renal failure, kidney disease or even a tumor because of its accompanying altered growth pattern. ${ }^{49}$

The initial increase in Bowman's space area of group $\mathrm{B}$ indicates active growth, which gradually decreased with time in the other groups. Morphometric analysis of the microanatomical alteration of the Bowman's space area is an adequate indicator of the change in total Bowman's and total glomerular areas. ${ }^{50}$ Expansion of Bowman's space is usually reflected by a reduction in the glomerular volume and could be an indicator of glomerular hyperfiltration..$^{50-54}$ The space within the capillaries is increased, while the 

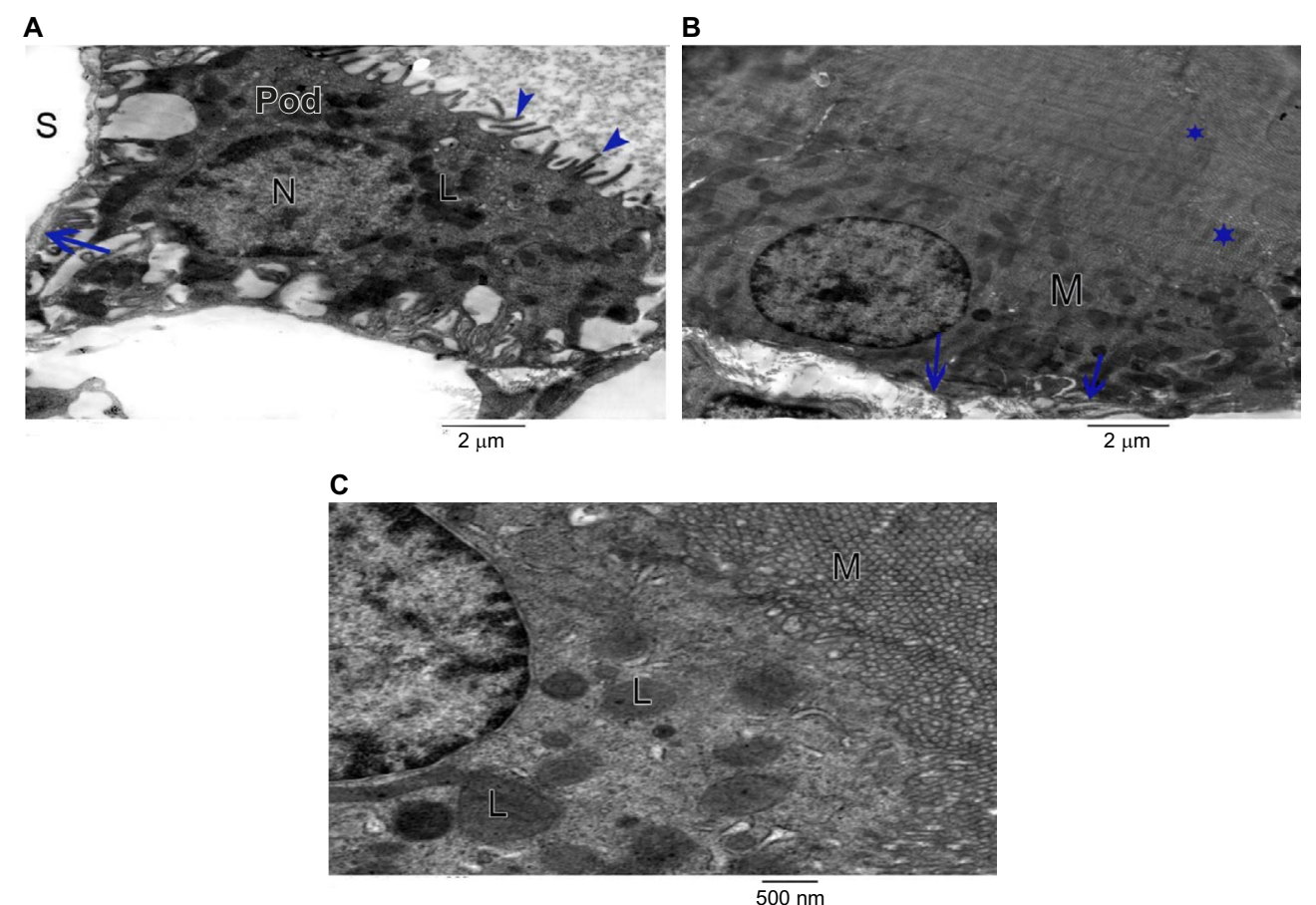

Figure 13 The 10 days group (group B). (A) An electron micrograph of ultrathin section of the renal glomerulus of group B rats ( 10 days group) showing disrupted basement membrane (arrow) with wide subpodocytic space (S). Podocytes (Pod) appear with disrupted minor processes (arrow head) and irregular nucleus (N) and numerous lysosomes (L). (B) Showing the proximal convoluted tubule lining cell lying on disrupted basement membrane (arrows). The cell has basal disarrangement of elongated mitochondria (M),but with the microvilli still intact at the luminal border (stars). (C) Proximal convuluted tubule lining cell (B) with prominant mitochodria (M) and lysosomes (L).

A

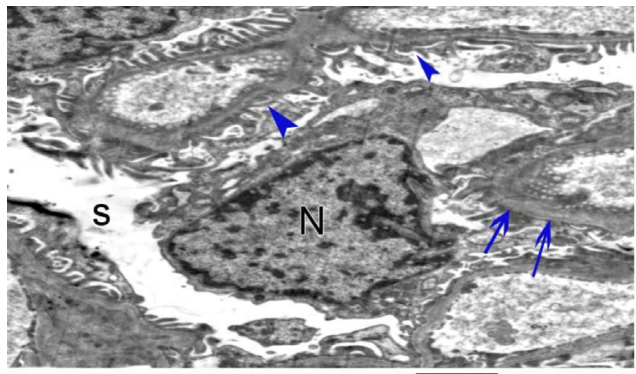

C

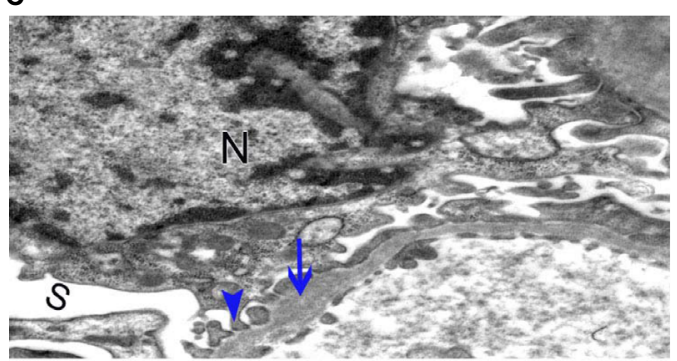

B

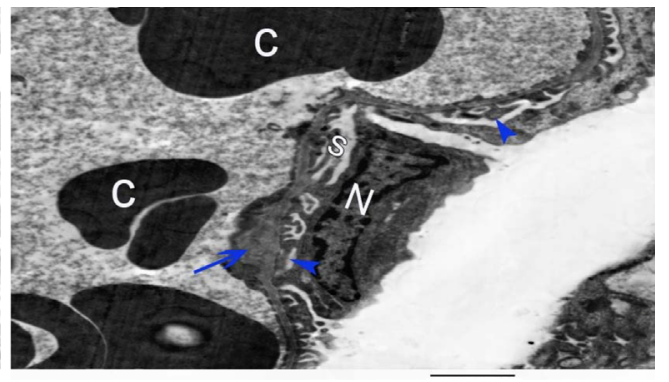

D

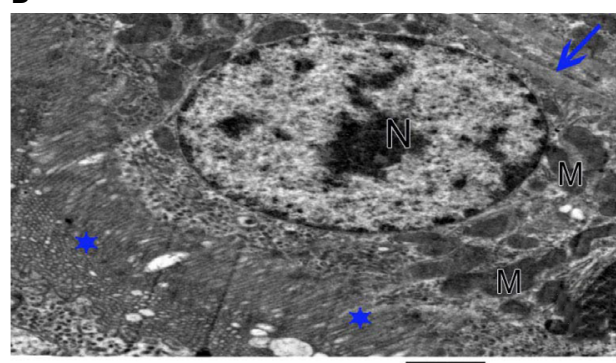

Figure 14 The 20 days group (group C). (A) Showing podocyte with disrupted irregular nucleus (N) and minor processes (arrow head). Thickened basement membrane (arrow) and widened subpodocytic space (S) are also seen. (B) An electron micrograph of the ultrathin section of the renal cortex of the 20 days group rat showing podocyte with disrupted irregular nucleus $(\mathrm{N})$ and minor processes (arrow head). Thickened basement membrane (arrow) and widened subpodocytic space (S) are also seen. RBCs are seen in congested glomerular capillaries (C). (C) An electron micrograph of the ultrathin section of the renal cortex of the 20 days group rat showing podocyte with disrupted irregular nucleus $(\mathrm{N})$ and minor processes (arrow head). Thickened basement membrane (arrow) and widened subpodocytic space (S) are also seen. (D) Showing the proximal convoluted tubule lining cell lying on thickened basement membrane (arrow). The cell has enlarged open face nucleus (N), irregular mitochondria (M) and microvilli at the luminal border (star).

Abbreviation: RBCs, red blood cells. 

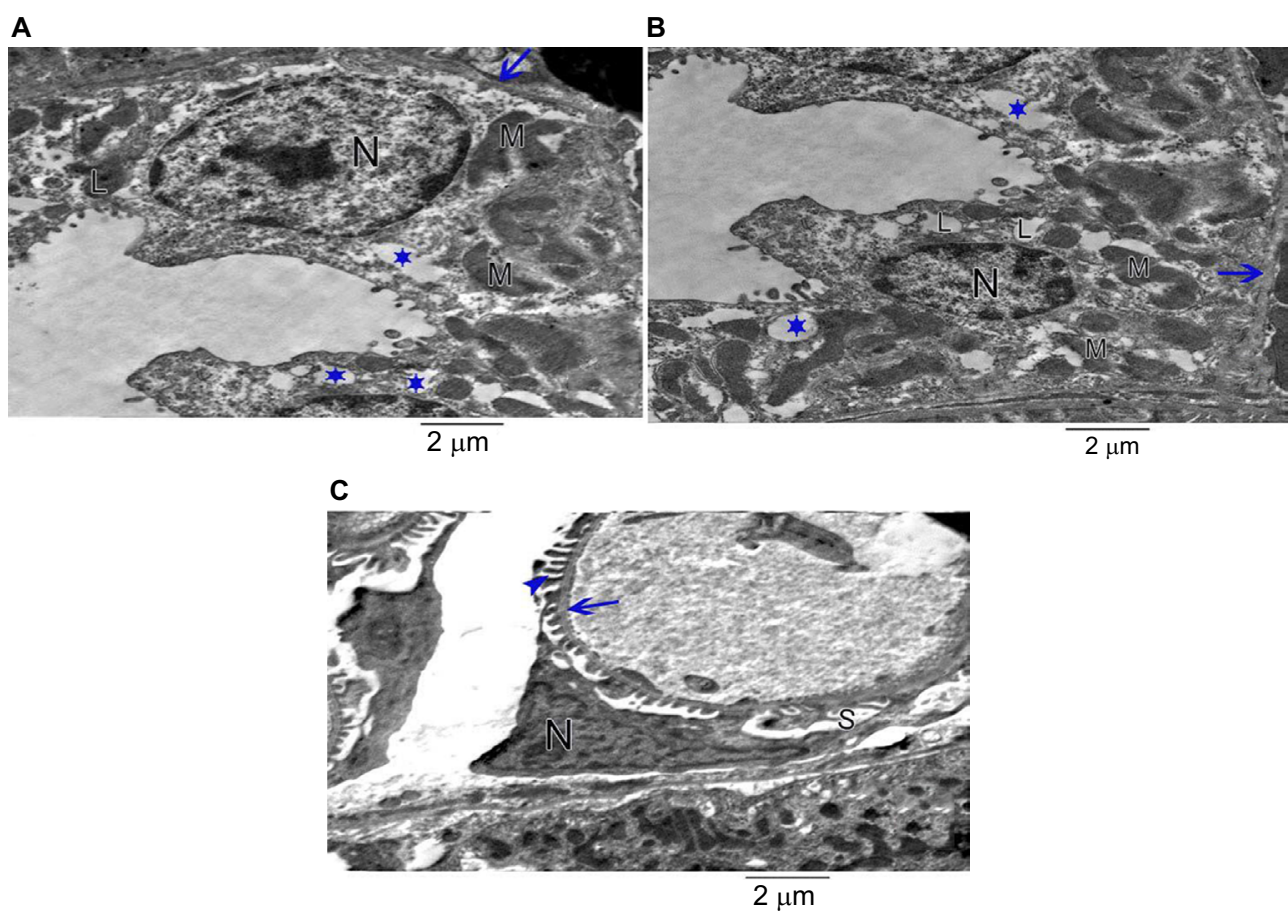

Figure 15 The 30 days group. (A) Showing the proximal convoluted tubule lining cell lying on thickened basement membrane (arrow). The cell has irregular enlarged nucleus $(\mathrm{N})$ and irregular arrangement of mitochondria (M), lysosomes $(\mathrm{L})$ and numerous vacuoles (star). Loss of microvilli is noticed. (B) Showing the proximal convoluted tubule lining cell lying on thickened basement membrane (arrow). The cell has irregular enlarged nucleus $(\mathrm{N})$ and irregular arrangement of mitochondria (M), lysosomes ( $L$ ) and numerous vacuoles (star). Loss of microvilli is noticed. (C) An electron micrograph of ultrathin section of the renal cortex of the 30 days group rat showing podocyte with irregular nucleus $(\mathrm{N})$ and minor processes (arrow head). Thickened basement membrane (arrow) and widened subpodocytic space (S) are also seen.

glomerular area is decreased; this might be due to the possible noncorrelation between the glomerular area and the glomerular cell proliferation. ${ }^{55}$

The low expression level of nestin is normal in adult cells, as its expression is downregulated when the cells are in nonstressed conditions, ${ }^{54,56}$ while its increased expression indicates cellular stress, which results in cellular proliferation and angiogenesis. ${ }^{57}$ Accordingly, decreased nestin expression indicates improvement of cellular stress. Our results showed increased expression of nestin in group $\mathrm{C}$, which might be an indicator of cellular proliferation and angiogenesis, and decreased expression in group $\mathrm{D}$, which might be a sign for improvement.

Glomerular basement membrane thickness is an important indicator of renal pathologic condition ${ }^{54}$ and is known to increase in rats until their death. ${ }^{58,59}$ These age-dependent changes are essentially due to gradual thickening of lamina densa and also due to increase in thickness with time after nephrectomy. ${ }^{60,61}$ In this study, statistical analysis related to the thickness of the basement membrane showed significant increase in the animals of group B compared to the control group and a nonsignificant increase in the other groups. The increase in thickness of the basement membrane in group B can be attributed to the initial focal segmental glomerulosclerosis in the remaining kidney after renal ablation. ${ }^{62}$ This seems to be caused by the increased cellular stress at this time, as it was accompanied by the most apparent pathologic changes in the podocytes.

Previous research reported that increase in membrane thickness is not necessarily associated with glomerular sclerosis or any other pathologic condition. ${ }^{58}$ Sometimes it occurs in spite of the improvement of the accompanying physiologic parameters. ${ }^{63}$ However, long-term studies showed that the increase in basement membrane thickness in nephrectomized rats is not accelerated after the sixth week, but paradoxically is reduced with aging. This can be explained by the fact that glomerular hypertrophy may lead to stretching of the glomerular capillary wall, and thereby thinning of the basement membrane. ${ }^{59}$

The podocytes gain a special importance as they line the basement membrane of the glomerulus, which, therefore, forms the final filtration barrier against proteinuria. ${ }^{64}$ They are the key regulator of the basement membrane in both physiologic and pathologic conditions. ${ }^{65}$ Injury of these cells leads to cascade of changes in the molecular architecture of the slit diaphragm due to reorganization of the foot processes. ${ }^{34,35,64}$

In this study, podocytes of the three nephrectomized rat groups showed disrupted minor processes, irregular nuclei, prominent mitochondria and numerous lysosomes, with disruption of Bowman's basement membrane and widening of 
the subpodocytic space. These data are in accordance with the findings of Van der Hauwaert et al, wherein the proximal tubular epithelial cells were found to have a major role in renal physiology and were among the cell types that were most sensitive to ischemia and nephrotoxicity. ${ }^{66}$ Proximal convoluted tubules of the 10 days group appeared with disrupted basement membrane. The lining cells had basal disarrangement of elongated mitochondria, but with the microvilli still intact at the luminal border. These irregular arrangements of the mitochondria and the changes in the endocytic vacuoles and lysosomes may signify that atrophy of the proximal convoluted tubule could possibly be in its early stages and might be associated with damaged tubular transport processes. ${ }^{67}$

The adaptive enlargement of the remaining kidney is associated with enlargement of the proximal tubule to resume the glomerular filtration rate. ${ }^{68}$ This hypertrophy was proved to be radial in the form of thickening of the wall without any increase in the number of cells. ${ }^{30}$

Some authors reported a rapidly changing pattern of gene expression within the first 24 hours in the hypertrophy of the kidney, which was assessed by measuring the messenger RNA with subsequent increase in the RNA/DNA ratio. ${ }^{69-71}$ However, other studies found no increase in the synthesis of DNA and/or expression of any immediate early genes. ${ }^{72}$

Many authors claimed that compensatory hypertrophy was found to be accompanied by an increase in many tissue markers such as epidermal growth factors, putative renotropic factors, heat shock protein 70, phospholipase D, androgens and insulin-like growth factor. ${ }^{69,73-77}$ Long-term studies ( $>20$ years) showed that the function of the remnant kidney in nephrectomized patients continued normally without deterioration in spite of prolonged hyperfiltration. ${ }^{78,79}$ Moreover, hypertrophy of the remnant kidney and additional improvements concerning the renal function also suggest that these progressions are adaptive and may be useful. ${ }^{45}$

Studies indicate that long-term complications after unilateral nephrectomy of the rat and the neonatal pup lead to hypertension in adults. Proteinuria and progressive loss of renal function leading to chronic renal failure occur mainly with old age..$^{49,80,81}$ In contrast, long-term observations in humans showed no obvious adverse effects, ${ }^{82}$ though the possibility of occurrence of chronic renal disease after nephrectomy is still evident. ${ }^{43}$

The correlation of these findings clearly indicates that the early changes in the kidney are signs of cellular stress. The structural changes detected in the remaining kidney following unilateral nephrectomy are much more complex than might be thought.

\section{Conclusion}

The association between ultrastructural changes and the expression of nestin confirms that this protein has a role in increasing the mechanical stability of the podocytes in order to facilitate any morphologic changes occurring in response to the tensile glomerular capillary wall. However, further studies investigating more remote ultrastructural changes and their relation with nestin expression are needed to confirm this relationship.

\section{Disclosure}

The authors report no conflicts of interest in this work.

\section{References}

1. Hosokawa Y, Tanaka N, Mibu H, et al. Follow-up study of unilateral renal function after nephrectomy assessed by glomerular filtration rate per functional renal volume. World J Surg Oncol. 2014;12:59.

2. Valla JS, Guilloneau B, Montupet P, et al. Retroperitoneal laparoscopic nephrectomy in children: preliminary report of six cases. J Laparoendosc Surg. 1996;6(Suppl 1):S55-S59.

3. Babic N, Huskic J, Nakas-Icindic E. Angiotensin converting enzyme activity in compensatory renal hypertrophy. Bosn J Basic Med Sci. 2007; 7(1):79-83.

4. Fleck C, Braunlich H. Kidney function after unilateral nephrectomy. Exp Pathol. 1984;25(1):3-18.

5. Katz AI, Epstein FH. Relation of glomerular filtration rate and sodium reabsorption to kidney size in compensatory renal hypertrophy. Yale $J$ Biol Med. 1967;40(3):222-230.

6. Seyer-Hansen K, Gundersen HJ, Osterby R. Stereology of the rat kidney during compensatory renal hypertrophy. Acta Pathol Microbiol Immunol Scand A. 1985;93(1):9-12.

7. Santos LS, Chin EW, Ioshii SO, Tambara Filho R. Surgical reduction of the renal mass in rats: morphologic and functional analysis on the remnant kidney. Acta Cir Bras. 2006;21(4):252-257.

8. Halliburton IW, Thomson RY. The effect of diet and of unilateral nephrectomy on the composition of the kidney. Cancer Res. 1967;27(9): $1632-1638$.

9. Shohat J, Erman A, Boner G, Rosenfeld J. Mechanisms of the early and late response of the kidney to contralateral nephrectomy. Ren Physiol Biochem. 1991;14(3):103-111.

10. Douglas-Denton R, Moritz KM, Bertram JF, Wintour EM. Compensatory renal growth after unilateral nephrectomy in the ovine fetus. $J \mathrm{Am}$ Soc Nephrol. 2002;13(2):406-410.

11. Liu B, Preisig PA. Compensatory renal hypertrophy is mediated by a cell cycle-dependent mechanism. Kidney Int. 2002;62(5):1650-1658.

12. Fong D, Denton KM, Moritz KM, Evans R, Singh RR. Compensatory responses to nephron deficiency: adaptive or maladaptive? Nephrology (Carlton). 2014;19(3):119-128.

13. Larsson L, Aperia A, Wilton P. Effect of normal development on compensatory renal growth. Kidney Int. 1980;18(1):29-35.

14. Galla JH, Klein-Robbenhaar T, Hayslett JP. Influence of age on the compensatory response in growth and function to unilateral nephrectomy. Yale J Biol Med. 1974;47(4):218-226.

15. Bonvalet JP, Champion M, Wanstok F, Berjal G. Compensatory renal hypertrophy in young rats: increase in the number of nephrons. Kidney Int. 1972;1(6):391-396.

16. Kaufman JM, Siegel NJ, Hayslett JP. Functional and hemodynamic adaptation to progressive renal ablation. Circ Res. 1975;36(2):286-293.

17. Dicker SE, Shirley DG. Mechanism of compensatory renal hypertrophy. J Physiol. 1971;219(3):507-523.

18. Valdivielso JM, Perez-Barriocanal F, Garcia-Estan J, Lopez-Novoa JM. Role of nitric oxide in the early renal hemodynamic response after unilateral nephrectomy. Am J Physiol. 1999;276(6 Pt 2):R1718-R1723. 
19. Sigmon DH, Gonzalez-Feldman E, Cavasin MA, Potter DL, Beierwaltes WH. Role of nitric oxide in the renal hemodynamic response to unilateral nephrectomy. J Am Soc Nephrology. 2004;15(6):1413-1420.

20. Hostetter TH, Olson JL, Rennke HG, Venkatachalam MA, Brenner BM. Hyperfiltration in remnant nephrons: a potentially adverse response to renal ablation. J Am Soc Nephrol. 2001;12(6):1315-1325.

21. Chamberlain RM, Shirley DG. Time course of the renal functional response to partial nephrectomy: measurements in conscious rats. Exp Physiol. 2007;92(1):251-262.

22. Shirley DG, Walter SJ. Acute and chronic changes in renal function following unilateral nephrectomy. Kidney Int. 1991;40(1):62-68.

23. Pollock CA, Nobes MS, Gyory AZ, Heng PT, Field MJ. Transferable circulating factors and epithelial sodium transport after unilateral nephrectomy in the rat. J Physiol. 1996;490(Pt 1):257-264.

24. Peters G. Introduction: history and problems of compensatory adaptation of renal functions and of compensatory hypertrophy of the kidney. Yale J Biol Med. 1978;51(3):235-245.

25. Joly E, Seqqat R, Flamion B, et al. Increased renal vascular reactivity to ANG II after unilateral nephrectomy in the rat involves 20-HETE Am J Physiol Regul Integr Comp Physiol. 2006;291(4):R977-R986.

26. Fleck C, Braunlich H. Stimulation of renal excretion of $\mathrm{p}$-aminohippurate $(\mathrm{PAH})$ after unilateral nephrectomy in adult and ageing rats. Physiol Bohemoslov. 1981;30(4):341-346.

27. Shea SM, Raskova J, Morrison AB. A stereologic study of glomerular hypertrophy in the subtotally nephrectomized rat. Am J Pathol. 1978;90(1):201-210.

28. Pollock CA, Lawrence JR, Field MJ. Tubular sodium handling and tubuloglomerular feedback in experimental diabetes mellitus. $\mathrm{Am} \mathrm{J}$ Physiol. 1991;260(6 Pt 2):F946-F952.

29. Dicker SE, Shirley DG. Compensatory renal growth after unilateral nephrectomy in the new-born rat. J Physiol. 1973;228(1):193-202.

30. Pfaller W, Seppi T, Ohno A, Giebisch G, Beck FX. Quantitative morphology of renal cortical structures during compensatory hypertrophy Exp Nephrol. 1998;6(4):308-319.

31. Guerrot D, Dussaule JC, Mael-Ainin M, et al. Identification of periostin as a critical marker of progression/reversal of hypertensive nephropathy. PLoS One. 2012;7(3):e31974.

32. Kretzler M, Koeppen-Hagemann I, Kriz W. Podocyte damage is a critical step in the development of glomerulosclerosis in the uninephrectomised-desoxycorticosterone hypertensive rat. Virchows Arch. 1994;425(2):181-193.

33. Wang G, Lai FM, Kwan BC, et al. Podocyte loss in human hypertensive nephrosclerosis. Am J Hypertens. 2009;22(3):300-306.

34. Perysinaki GS, Moysiadis DK, Bertsias G, et al. Podocyte main slit diaphragm proteins, nephrin and podocin, are affected at early stages of lupus nephritis and correlate with disease histology. Lupus. 2011;20(8):781-791.

35. Yasuno K, Ishihara S, Saito R, et al. Early-onset podocyte injury and glomerular sclerosis in osborne-mendel rats. JVet Med Sci. 2010;72(10): 1319-1327.

36. Le Hir M, Keller C, Eschmann V, Hahnel B, Hosser H, Kriz W. Podocyte bridges between the tuft and Bowman's capsule: an early event in experimental crescentic glomerulonephritis. J Am Soc Nephrol. 2001;12(10) 2060-2071.

37. Wagner N, Wagner KD, Scholz H, Kirschner KM, Schedl A. Intermediate filament protein nestin is expressed in developing kidney and heart and might be regulated by the Wilms' tumor suppressor Wt1. Am J Physiol Regul Integr Comp Physiol. 2006;291(3):R779-R787.

38. Su W, Fang C, Yang HC, Gu Y, Hao CM. Expression of nestin in human kidney and its clinical significance. Zhonghua Bing Li Xue Za Zhi. 2008;37(5):309-312. Chinese.

39. Nagib AM, Refaie AF, Hendy YA, et al. Long term prospective assessment of living kidney donors: single center experience. ISRN Nephrol. 2014;2014:502414.

40. Averbukh Z, Bogin E, Cohn M, et al. The renotrophic factor, a persistent stimulus that crosses the placenta in mice. J Physiol. 1988;404:31-38.
41. Hayslett JP. Functional adaptation to reduction in renal mass. Physiol Rev. 1979;59(1):137-164.

42. Campbell SC, Novick AC. Expanding the indications for elective partial nephrectomy: is this advisable? Eur Urol. 2006;49(6):952-954.

43. Drukker A. Organ donation and kidney sales. Lancet. 1998;352(9126): 483-484.

44. Argiles A, Mourad G, Basset N, et al. Acute adaptative changes to unilateral nephrectomy in humans. Kidney Int. 1987;32(5):714-720.

45. Martin WF, Armstrong LE, Rodriguez NR. Dietary protein intake and renal function. Nutr Metab (Lond). 2005;2:25.

46. Brenner BM. Nephron adaptation to renal injury or ablation. Am J Physiol. 1985;249(3 Pt 2):F324-F337.

47. Sidorova VF, Gorbunova VD. Comparative characteristics of compensatory renal hypertrophy following unilateral nephrectomy in mature and old rats. Biull Eksp Biol Med. 1976;82(11):1394-1397.

48. Mulroney SE, Woda C, Johnson M, Pesce C. Gender differences in renal growth and function after uninephrectomy in adult rats. Kidney Int. 1999;56(3):944-953.

49. Woods LL. Neonatal uninephrectomy causes hypertension in adult rats. Am J Physiol. 1999;276(4 Pt 2):R974-R978.

50. Javaid B, Olson JL, Meyer TW. Glomerular injury and tubular loss in adriamycin nephrosis. J Am Soc Nephrol. 2001;12(7):1391-1400.

51. Henegar JR, Bigler SA, Henegar LK, Tyagi SC, Hall JE. Functional and structural changes in the kidney in the early stages of obesity. $J \mathrm{Am}$ Soc Nephrol. 2001;12(6):1211-1217.

52. Tobar A, Ori Y, Benchetrit S, et al. Proximal tubular hypertrophy and enlarged glomerular and proximal tubular urinary space in obese subjects with proteinuria. PLoS One. 2013;8(9):e75547.

53. Olivetti G, Anversa P, Melissari M, Loud AV. Morphometry of the renal corpuscle during postnatal growth and compensatory hypertrophy. Kidney Int. 1980;17(4):438-454.

54. Namiki J, Suzuki S, Masuda T, Ishihama Y, Okano H. Nestin protein is phosphorylated in adult neural stem/progenitor cells and not endothelial progenitor cells. Stem Cells Int. 2012;2012:430138.

55. Sammut S, Behr L, Hekmati M, Gubler MC, Laborde K, Lelievre Pegorier M. Compensatory renal growth after unilateral or subtotal nephrectomy in the ovine fetus. Pediatric research. 2013;74(6):624-632.

56. Suzuki S, Namiki J, Shibata S, Mastuzaki Y, Okano H. The neural stem/progenitor cell marker nestin is expressed in proliferative endothelial cells, but not in mature vasculature. J Histochem Cytochem. 2010;58(8):721-730.

57. Said E, Said SA, Gameil NM, Ammar EM. Modulation of thioacetamide-induced liver fibrosis/cirrhosis by sildenafil treatment. Can J Physiol Pharmacol. 2013;91(12):1055-1063.

58. Dodane V, Chevalier J, Bariety J, Pratz J, Corman B. Longitudinal study of solute excretion and glomerular ultrastructure in an experimental model of aging rats free of kidney disease. Lab Invest. 1991;64(3):377-391.

59. Dubrulle MP, Terzi F, Gubler MC, Kleinknecht C, Schaeverbeke M. Changes in thickness and anionic sites of the glomerular basement membrane after subtotal nephrectomy in the rat. Am J Pathol. 1992;141(6):1481-1489.

60. McCarthy RA, Steffens WL, Brown CA, Brown SA, Ard M, Finco DR. Effects of dietary protein on glomerular mesangial area and basement membrane thickness in aged uninephrectomized dogs. Can J Vet Res. 2001;65(2):125-130.

61. Haylor J, Chowdry J, Baillie H, Cope G, el Nahas AM. Renal function and morphometry in the dwarf rat following a reduction in renal mass. Nephrol Dial Transplant. 1996;11(4):643-650.

62. Chen A, Sheu LF, Ho YS, et al. Experimental focal segmental glomerulosclerosis in mice. Nephron. 1998;78(4):440-452.

63. Aunapuu M, Pechter U, Arend A, Suuroja T, Ots M. Ultrastructural changes in the remnant kidney (after 5/6 nephrectomy) glomerulus after losartan and atenolol treatment. Medicina (Kaunas). 2003;39(10):975-979.

64. Li K, Wang J, Yin X, Zhai X, Li Z. Alteration of podocyte protein expression and localization in the early stage of various hemodynamic conditions. Int J Mol Sci. 2013;14(3):5998-6011. 
65. Marshall CB. Rethinking glomerular basement membrane thickening in diabetic nephropathy: adaptive or pathogenic? Am J Physiol Renal Physiol. 2016;311(5):F831-F843.

66. Van der Hauwaert C, Savary G, Gnemmi V, et al. Isolation and characterization of a primary proximal tubular epithelial cell model from human kidney by CD10/CD13 double labeling. PLoS One. 2013;8(6):e66750.

67. Moller JC, Skriver E, Olsen S, Maunsbach AB. Ultrastructural analysis of human proximal tubules and cortical interstitium in chronic renal disease (hydronephrosis). Virchows Arch A Pathol Anat Histopathol. 1984;402(3):209-237.

68. Endele S, Klein S, Richter S, et al. Renal phenotype in heterozygous Lmx1b knockout mice (Lmx1b+/-) after unilateral nephrectomy. Transgenic Res. 2007;16(6):723-729.

69. Escher G, Vogt B, Beck T, Guntern D, Frey BM, Frey FJ. Reduced 11 beta-hydroxysteroid dehydrogenase activity in the remaining kidney following nephrectomy. Endocrinology. 1998;139(4):1533-1539.

70. Bhojwani D, Kang H, Menezes RX, et al; Children's Oncology Group Study; Dutch Childhood Oncology Group; German Cooperative Study Group for Childhood Acute Lymphoblastic Leukemia. Gene expression signatures predictive of early response and outcome in high-risk childhood acute lymphoblastic leukemia: a children's oncology group study [corrected]. J Clin Oncol. 2008;26(27):4376-4384.

71. Moskowitz DW, Liu W. Gene expression after uninephrectomy in the rat: simultaneous expression of positive and negative growth control elements. J Urol. 1995;154(4):1560-1565.

72. Loffing J, Le Hir M, Kaissling B. Modulation of salt transport rate affects DNA synthesis in vivo in rat renal tubules. Kidney Int. 1995;47(6): 1615-1623.
73. Muchaneta-Kubara EC, Sayed-Ahmed N, el Nahas AM. Subtotal nephrectomy: a mosaic of growth factors. Nephrol Dial Transplant. 1995;10(3):320-327.

74. Gatalica Z, Moehren G, Hoek JB. Unilateral nephrectomy selectively stimulates phospholipase D in the remaining kidney. Biochim Biophys Acta. 1993;1177(1):87-92.

75. Berger FG, Gross KW, Watson G. Isolation and characterization of a DNA sequence complementary to an androgen-inducible messenger RNA from mouse kidney. J Biol Chem. 1981;256(13): 7006-7013.

76. Sawczuk IS, Olsson CA, Buttyan R, et al. Gene expression in renal growth and regrowth. J Urol. 1988;140(5 Pt 2):1145-1148.

77. Wolf G. Cellular mechanisms of tubule hypertrophy and hyperplasia in renal injury. Miner Electrolyte Metab. 1995;21(4-5):303-316.

78. Higashihara E, Horie S, Takeuchi T, Nutahara K, Aso Y. Long-term consequence of nephrectomy. J Urol. 1990;143(2):239-243.

79. Regazzoni BM, Genton N, Pelet J, Drukker A, Guignard JP. Long-term followup of renal functional reserve capacity after unilateral nephrectomy in childhood. J Urol. 1998;160(3 Pt 1):844-848.

80. Woods LL, Weeks DA, Rasch R. Hypertension after neonatal uninephrectomy in rats precedes glomerular damage. Hypertension. 2001;38(3):337-342.

81. Ohishi A, Suzuki H, Nakamoto H, et al. Status of patients who underwent uninephrectomy in adulthood more than 20 years ago. Am J Kidney Dis. 1995;26(6):889-897.

82. Saran R, Marshall SM, Madsen R, Keavey P, Tapson JS. Long-term follow-up of kidney donors: a longitudinal study. Nephrol Dial Transplant. 1997;12(8):1615-1621.

\section{Publish your work in this journal}

The International Journal of Nephrology and Renovascular Disease is an international, peer-reviewed open access journal focusing on the pathophysiology of the kidney and vascular supply. Epidemiology, screening, diagnosis, and treatment interventions are covered as well as basic science, biochemical and immunological studies. The manuscript management system is completely online and includes a very quick and fair peer-review system, which is all easy to use. Visit http://www. dovepress.com/testimonials.php to read real quotes from published authors. 